\title{
Digital Piracy, Teens, and the Source of Advice: An Experimental Study
}

Matthew J. Hashim, Karthik N. Kannan, Sandra Maximiano, and Jackie Rees Ulmer

Matthew J. Hashim (mhashim@email.arizona.edu)

The University of Arizona, Department of MIS, P.O. Box 210108, Tucson, AZ 85721-0108, USA

Karthik N. Kannan (kkarthik@purdue.edu)

Purdue University, Department of Management, 403 W. State Street, West Lafayette, IN 47907-2056, USA

Sandra Maximiano (maximiano@purdue.edu)

Purdue University, Department of Economics, 403 W. State Street, West Lafayette, IN 47907-2056, USA

Jackie Rees Ulmer (jrees@purdue.edu)

Purdue University, Department of Management, 403 W. State Street, West Lafayette, IN 47907-2056, USA

Matthew J. Hashim is an Assistant Professor of Management Information Systems in the Eller College of Management, The University of Arizona. He received his Ph.D. in Management with a specialization in Management Information Systems from the Krannert School of Management at Purdue University. His research interests include behavioral aspects of digital piracy, management of information security, and electronic commerce strategy. He has presented his research at major conferences and workshops such as the Workshop on Information Systems and Economics (WISE), the Workshop on the Economics of Information Security (WEIS), INFORMS, and the North American Economic Science Association.

Karthik N. Kannan is an Associate Professor of Management in the Information Systems area in the Krannert School of Management, Purdue University. He received his Ph.D. in Information Systems from the Heinz College of Public Policy at Carnegie Mellon University. His research interests include markets and pricing of information goods/services through auctions, and economics of information security. His research has been published in Management Science, Information Systems Research, Journal of Organizational Computing and Electronic Commerce, International Journal of Electronic Commerce, Economic Letters, Marketing Letters, and Review of Marketing Science. He has also presented his research at major conferences and workshops such as Workshop on Information Technology and Systems (WITS), Workshop on Information Systems and Economics (WISE), International Conference on Information Systems (ICIS), and Conference on Information System and Technology (CIST). His papers have won the Best Paper Awards in the $10^{\text {th }}$ and the $15^{\text {th }}$ annual Workshop on Information Technology and Systems. He currently serves/has served as an Associate Editor for Management Science, Information Systems Research, and MIS Quarterly.

Sandra Maximiano is an Assistant Professor of Economics in the Krannert School of 
Management, Purdue University. She received her Ph.D. in Economics from the University of Amsterdam. Her research interests include fields such as behavior, experimental, organizational, personal, and labor economics, with a main focus on the role of social and moral preferences in economic decisions. Her research has been published in Games and Economic Behavior, Economic Journal, and The Review of Economics and Statistics.

Jackie Rees Ulmer is an Associate Professor of Management in the Information Systems area in the Krannert School of Management, Purdue University. She received her Ph.D. in Decision and Information Sciences from the Warrington College of Business Administration at the University of Florida. Her research interests include machine learning and risk management for information security. She has published research articles in Information Systems Research, Journal of Information Systems, INFORMS Journal of Computing, Decision Sciences, Communications of the ACM, European Journal of Operational Research, Decision Support Systems, IEEE Transactions on Systems, Man, and Cybernetics: Part C, and Information Technology and Management. She serves on the editorial boards of Decision Sciences, Information Technology and Management, and Communications of the AIS.

Acknowledgements: The authors would like to thank Kory Garner for his research assistance. The authors also thank Ravi Bapna, Anitesh Barua, two anonymous reviewers, and participants of the 2012 North American Economic Science Association Conference, for their helpful comments. Karthik Kannan and Jackie Rees Ulmer thank the Center for Education and Research in Information Assurance and Security (CERIAS) at Purdue University.

Abstract: The objective of our paper is to determine the effect of piracy advice from various sources on music consumer behavior. Specifically, does it matter if the source of advice has a stake in the outcome of the piracy decision? Does it matter if the source of advice has a social tie with the advisee? Accordingly, we conduct a lab experiment using teenagers and their parents as subjects, increasing the realism of the context by sampling potential pirates and their parents. Treatments represent various sources of piracy advice (e.g., the teen's parent, a record label, or an external regulator). Subjects make decisions playing our new experimental game - The Piracy Game - extended from the volunteer's dilemma literature. Interestingly, subjects respond negatively to advice from record labels over time, purchasing fewer songs as compared to other sources such as the subject's parent. The existence of a social tie between the advisor and the subject assists in mitigating piracy, especially when a parent is facing potential penalties due to his/her child's behavior. An external regulator, having no social tie or stake in the decision, provides the least credible source of advice, leading to the greatest amount of piracy. Our analyses not only provide managerial insights but also develop theoretical understanding of the role of social ties in the context of advice.

Keywords: piracy, advice, communication, experimental economics, volunteer’s dilemma

\section{$\underline{\text { Introduction }}$}

Digital goods manufacturers and related organizations such as the RIAA and the MPAA attribute 
significant losses to digital piracy (e.g., \$12.5 Billion loss from software piracy [63]). ${ }^{1}$ To limit losses, these organizations are increasingly nudging pirates through education and advice to disengage from pirating. Some of the nudging is done directly by an interested party, e.g., a vendor or a music artist delivers the message via YouTube videos or public statements. Whereas in other cases, it is delivered through someone who may have a social tie with the pirate, e.g., teachers and parents. Even though there have been some successful anecdotes of limiting piracy (e.g., 2D Boy [1]), it is not clear when nudging is effective in general. The objective in our paper is to develop an understanding of how nudging varies with the source of advice.

Adolescents and young adults are generally recognized to be the population extensively engaged in digital piracy because of reasons such as their technical savviness, their limited financial means, and general acceptance of piracy [55, 59]. It is this target population that organizations such as the MPAA and the RIAA attempt to nudge either directly or indirectly (e.g., Knopper [67]). Direct nudges or advice from recording artists/labels may be perceived as self-centered and may not be effective. Similarly, indirect nudges may not be effective either because the target population is often perceived to be engaged in a "purposeful flight away" from their parents. Yet, the RIAA and the MPAA continue to invest extensively to develop (direct and indirect) programs. Interestingly, there is little insight available from prior literature to guide managerial actions. For example, in the developmental psychology literature, Poon and Pittinsky [82] identify very little prior empirical work on parental advice (see the related literature section for details). Accordingly, our paper analyzes how the sources compare not only in terms of limiting piracy, but also in terms of enabling purchases of digital goods. Using these two metrics, we answer the following questions: Does sending informative advice matter in a framed piracy context? Who is the best source of advice? Does it matter if the source of advice has a stake in

\footnotetext{
${ }^{1}$ Recording Industry Association of America (RIAA) and Motion Picture Association of America (MPAA).
} 
the outcome of the piracy decision? Does it matter if the source of advice has a social tie with the advisee?

We answer the aforementioned questions using an experimental lab setting and we chose experiments for the following reasons. First, studying the aforementioned questions using secondary data is quite difficult, if not impossible. Second, tracking behavior in illegal contexts (such as piracy) is challenging because participants may explicitly behave differently when they realize they are being tracked. Third, information flows cannot be easily controlled in real scenarios unlike in controlled randomized trials. Therefore, attributing the differences in the outcomes to the policy changes may be tenuous. Fourth, while randomized field trials would be ideal, the DMCA (Digital Millenium Copyright Act) and other legal obstacles limit our ability to conduct field experiments.

Our experiment involves a volunteer's dilemma game, which models free-riding problems in a public goods context. A key motivation for considering a public goods game is that many economists, including Varian [100], treat information goods (e.g., music, movies, software) as public goods. $^{2}$ We consider a variant of the volunteer's dilemma game that explicitly accounts for subjects' decisions to engage in piracy versus purchasing the good. This distinction does not exist even in a typical public goods game and is a distinctive feature of our game. Moreover, the subject pool of parents and their teens is appropriately unique for our context - our sample is similar in age as the population dealt with in the piracy context - adding to the generalizability of our study. ${ }^{3}$

We consider four different treatments in our experiments that vary in terms of the source of

\footnotetext{
2 Although music, movies, or software being a non-rivalrous good is generally recognized, there is debate about whether it is a non-exclusive good. Music producers, movie producers, and software developers typically consider that copyright laws restrict music from being non-exclusive. ${ }^{3}$ Peters et al. [80] implement a public goods game with a subject pool of grade-school children and their parent(s) in a lab setting to test the Rotten Kid Theorem. They find that children tend to free ride more than their parent(s), regardless of if the children are playing the game with their parent(s) or with strangers. Our study is different from theirs in the type of game played, the context, the appropriateness of our subjects'
} 
advice. These treatments vary along two dimensions - one is whether the source has a social tie ${ }^{4}$ with the subjects and the other is whether the source has a stake in the game. When dealing with the social tie, we only focus on advice from parents. Expanding on the four treatments, we have: (a) Social tie and stake: advice from parents incurring penalties for their respective teens' piracy decisions (reflecting penalties from legal actions); (b) Social tie and no stake: advice from parents without any penalties for their teens' actions; (c) No social tie but stake: advice from the private provisioner of the public good; and (d) No social tie and no stake: advice from a third party regulator not directly affected because of piracy/purchase decisions. These treatments reflect the typically-used educational approaches quite well.

The following are some of the salient results from our analyses. As expected, subjects exhibit non-standard preferences. The non-standard preferences vary in terms of implications across treatments. When a parent is the source of advice, the amount of piracy appears to be lower compared to when the advisor is an unrelated third party (e.g., a record label or industry regulator). Surprisingly, the record label as the source of advice results in the lowest purchasing levels as compared to the other treatments. The most effective treatment in reducing pirating and increasing purchasing is when the source of advice is the parent who is being punished for their teens' pirating actions. Whereas the third party regulator - which does not have a social tie or a stake in the outcome - is the least effective source of advice at influencing pirating. Toward the end of the paper, we discuss how these results contribute to the body of knowledge in various streams of literature.

The rest of the paper is organized as follows. We review the related literature next, followed by our game and theoretical predictions. We then introduce the treatment design and hypotheses,

ages to the context, as well as the theories of interest to our study.

${ }^{4}$ Consistent with prior sociology literature, we treat parental ties as social ties (e.g., McAdam and Paulsen [74]). 
and subsequently describe our experimental implementation. Finally, we discuss our results and provide implications of the study in the conclusion.

\section{$\underline{\text { Related Literature }}$}

Our paper primarily relates and contributes to four main research streams: developmental psychology and advice, experiments on the effects of bilateral and unilateral communication, social ties in experiments, and literature on digital piracy. ${ }^{5}$ Each subsection below considers each of the streams.

\section{Developmental Psychology and Advice}

Young adults and teens - the target population in the piracy context - are at a phase in their life when they develop autonomy so as not to rely on parents’ support when making their way through the world. During their "purposeful flight away” from their parents, their ties to the parents may appear to be restraining and any parental advice may appear to be ineffective at the first glance. However, Allen and Land [4] point to their prior work to show that even as adolescent bonds to parents transition towards increased autonomy, the transition is tightly coupled with a stronger and lasting relationship of a goal-correcting nature. In other words, as adolescents become more self-sufficient, they increasingly take into account the parent's goals, advice, and directives when choosing their actions (e.g., maintain trust, manage goals). So, in effect, the RIAA and MPAA's attempts at using advice to nudge piracy-related behavior does not appear to be too out of place.

As regards the effectiveness of the source of advice, we first focus on if and when parental advice is effective. Only a "small amount of empirical research has examined the transmission of

\footnotetext{
${ }^{5}$ Our paper relates to experiments in public goods, which has been extensively studied. It has recognized the dominant strategy of free-riding behavior, heterogeneity in cooperation by subjects, as well as design features in public good games [6, 25, 39, 49, 71]. Various other aspects of the public good game have also been considered. For example, punishment and rewards from a decentralized and exogenously imposed perspective $[8,45,69,73,78,85]$, and punishment originating in a centralized manner from the experimenter [7, 37, 44, 69]. Group formation as a mechanism to mitigate free-riding has also been considered [3, 24, 31, 68, 95]. Regarding information feedback, some papers directly explore
} 
advice from parents down to their children” [82]. Furthermore, we are not aware of any significant additions in the literature between 2005 and now either. A large number of papers on parental advice are focused on divorced households. Among others, one of the papers closely related to ours is Turrisi et al. [97]. In that work, Turrisi et al. [97] conduct a field experiment in which parental involvement in advising new high school graduates is manipulated. The experimenters selectively provide an educational pamphlet to some parents about drinking in college. Relative to the control group in which parents did not receive any information, there was a reduction in the behavior of the experimental group. Similar results have been observed when advice is used in combination with another mechanism (e.g., parental support, parental influence, monitoring of behavior, instituting consequences) to generate the desired outcome $[9,18,103]$.

From the aforementioned papers, there is some evidence regarding the effectiveness of parental advice. Even then, we are not aware of insights available from prior literature to compare the various sources of advice. It is possible that the "purposeful flight away" from parents could lead adolescents and young adults to be more likely to heed the advice from third parties such as the RIAA and the MPAA. Therefore, questions about the value from parental advice as opposed to other sources of advice remain open and which is also the focus of our paper. We next survey some works from the experimental economics literature that are loosely related to advice.

\section{Experimental Work on Communication}

Advice may be treated as a unilateral type of communication. Therefore, we briefly survey the related experimental work on communication. We first consider public good contexts, where much of the prior work has considered communication amongst contributors to a public good. A few papers have studied how the nature of communication improves coordination. Isaac and 
Walker [64] show that face-to-face communication between rounds in a public good game significantly reduces the free-riding problem even though the communication is non-binding, meaning the subjects do not have to implement the results of their communication in their decision. Bochet et al. [16] find that text-based communication is nearly as efficient as face-to-face at mitigating free-riding. Cason and Khan [21] show that communication mitigates the free-riding problem, both with and without the ability for subjects to perfectly or imperfectly monitor the contributions of others to the public good. Kroll et al. [70] explores the role of voting as a communication mechanism to achieve a majority outcome in a public good game. If votes made by subjects are non-binding, the subjects in their game dismiss the majority opinion as cheap talk. It is however possible to sustain cooperation if a binding mechanism is installed that punishes those that deviate from the group majority. Chaudhuri et al. [26] finds that greater contributions to the public good result when advice about how to play the game is given as common knowledge to subjects.

Communication as a means to improve coordination has been studied in other contexts also. In a dictator game, Mohlin and Johannesson [76] find that allocations increase significantly when the dictator receives communication from the recipient. Similarly, in trust games, Ben-Ner and Putterman [12] show that prior communication increases trust, resulting in greater cooperation and outcomes. Charness and Dufwenberg [23] experimentally explore the impact of communication on cooperation in a trust game, where communication takes the form of passing notes between subjects in different rooms. They find an associated impact on promises made (and kept), measuring the existence of guilt aversion as a type of social preference.

In the context of unilateral communication, we specifically refer to a seminal piece by Crawford and Sobel [34]. They study how advice is interpreted differently depending on how 
well the sender's incentives are aligned with the receiver's. In their Sender-Receiver game, the sender is privy to some information affecting the receiver's outcome. Using that scenario, they find that when the interests do not align between the sender and the receiver, the communication is interpreted as cheap talk. Obviously, there are other additional factors that dictate the consumption of advice. For example, Healy [58] shows how heterogeneity in the source of advice - specifically, nationality - leads to differing outcomes. Our paper also builds on Crawford and Sobel [34] to consider how the social tie with the source of advice affects the outcomes, which leads us to survey the next stream of literature.

\section{Social Ties in Experiments}

Subjects' behavior is recognized to depend not only on their intrinsic preferences, but also on the strength of the relationships within which social exchange is embedded [54]. There is a small but growing interest in experimental economics to consider the role of social ties.

Much of the prior work focuses on comparing social preferences when interacting with individuals, with whom the subjects have a strong as opposed to a weak social tie. Using a simple bargaining game - the ultimatum game - Polzer et al. [81] show that friends demand less than strangers to reach an agreement. Hoffman et al. [60] vary the social distance between the subjects and the experimenter in a dictator game and find that social distance influences fairness. In particular, they support the hypothesis of a negative correlation between offers and social distance. Glaeser et al. [52] match subjects at various levels of social ties in a trust game and show that as social ties get stronger there is a shift towards greater trust and trustworthiness. Reuben and van Winden [86] focus on the effect of social ties on negative reciprocity and find that friends are more likely to punish the proposer for an unkind action. Leider et al. [72] conduct an online field experiment using a real world social network to disentangle possible explanations 
of pro-social behavior. They find that intrinsic altruism towards a stranger, social ties, and the prospect of future interactions all play a role in giving behavior. Social ties also affect lying. Chakravarty et al. [22] find that subjects are less likely to lie to friends than to strangers. The effect is particularly strong for selfish individuals as opposed to pro-social ones.

As regards free-riding behavior, an aspect relevant to our paper, social ties are found to have a diminishing effect. Gächter and Fehr [48] explore whether social approval decreases free-riding in a repeated public goods game. Despite finding that social approval alone does not improve cooperation, cooperation is enhanced in cases where subjects familiarize themselves with each other. Similarly, in an experimental microfinance game, Abbink et al. [2] observe that acquaintances have a higher willingness to cooperate than strangers at the beginning of the experiment, but they also retaliate more as they are less willing to tolerate free-riding behavior by others.

Social ties have been incorporated in theoretical models also. van Dijk and van Winden [99] consider the interplay between the provision of public goods and the formation of social ties. They define a social tie between two individuals as the extent to which they care about each other’s well-being. van Dijk et al. [98] use public goods experiments to confirm the theoretical result that the social tie formation depends on the success of the game.

The role of social ties in the context of advice has not been studied in the prior literature to the best of our knowledge. Therefore, we aim to study how advice plays a role when the source of advice varies along the two dimensions: one where the source has a stake in the outcome of advisee's decision and the other where the source has a social tie with the advisee. As mentioned before, the two dimensional analysis on the source of advice builds on Crawford and Sobel [34].

\section{Related Digital Piracy Literature}


The existing Information Systems (IS) research has focused primarily on behavioral and analytical approaches to study piracy. Early IS work on piracy prioritized the factors most important to pirates [29]. They identify the cost of the digital good as the most important one, followed by the pirates' desire to sample before buying. Many analytical works have focused on the pricing effects of digital goods in pirate versus purchase decisions [40, 50, 66]. A few other analytical models explore piracy in conjunction with other strategies implied to limit the implications of piracy. Chellappa and Shivendu [28] deal with sampling strategies along with pricing. Gopal and Sanders [53] and Sundararajan [94] focus on technology deterrence in the context of piracy. Bhattacharjee et al. [15], and Bhattacharjee et al. [14] study how piracy may be limited using bundling strategies along with technology protection. ${ }^{6}$ Chellappa and Shivendu [27] suggest that implementing various global standards is a way to limit losses due to piracy across geographic regions. Bhattacharjee et al. [13] study piracy in emerging markets by modeling consumer search of digital experience goods, finding retailer profits are maximized in conjunction with some level of piracy. Clemons et al. [32] explore technology protection in newly vulnerable markets (i.e., exposure to digitization) that can be implemented as a defensive strategy against piracy for recording artists.

From the behavioral perspective of piracy, initial work was rooted in modeling piracy as an ethical decision-making process [96], illustrating support for norms and perceived consequences influencing ethical judgment and moral intention. Many of the factors identified in their work have been included in follow-up research to suggest strategies to enhance customer retention by addressing intentions to use legal software [57, 79, 101]. These strategies include pricing, communication, and legal actions, among others, to mitigate piracy [30, 77]. We experimentally

${ }^{6}$ Although we do not directly address bundling in our research, we do incorporate the inability of firms to adequately protect their digital goods with technology by assuming the good may be shared publicly without restriction. 
test advice as an educational strategy in our paper, moving beyond conjecture in the prior literature. Our approach is especially useful given our experimental treatments that are designed to tease apart implications based upon the source of advice.

On the experimental/behavioral economics front, we are only aware of our own work: Hashim et al. [56], which examines the effect of information about others' contributions to a public good when the information is targeted to specific subgroups of players in the game. The key findings are that randomly providing information about others' contribution has a negative effect on behavior, and that targeting the same information to those contributing above the average leads to the highest amount of coordination.

Overall, the ability to address the gaps discussed in the prior literature, with the strong parallel between piracy and free-riding in public goods, presents an appropriate foundation for the development and introduction of our piracy game.

\section{The Game and Theoretical Predictions}

Our game - the piracy game - considers $n$ music consumers and a record label. In the game only the consumers make a decision although the record label receives the proceeds generated by consumers' decisions. The stylized model represents a situation in which each consumer attempts to free ride on the behavior of other members in a dynamic setting. Next we present the details of our piracy game followed by the equilibrium analysis.

\section{The Piracy Game}

We consider a group of $n$ symmetric, risk-neutral consumers that make $M$ decisions during a finite period of time. In particular, at each decision node, consumers decide independently and anonymously whether to buy a song from a record label, whether to download a song, or do nothing. After the decision is submitted, the consumer is again required to choose between one 
of the three actions. Consumers make the same decision repeatedly until time $T$ ends.

Each consumer has a private endowment of $e>0$ that can be used to buy songs from the record label during the amount of time $T$. The record label is endowed with $S$ number of songs. The price of each song is normalized to one. Songs are assumed to have a characteristic of a public good, and once bought they are readily available for others to download/pirate. Consumers in our game do not have the ability to restrict other consumers from downloading their purchased songs. However, each consumer can decide whether or not (s)he downloads for free (i.e., pirate) a song purchased by one of the other consumers. Besides the initial endowment $e$, each consumer is also endowed with $\bar{b}$ number of songs. The initial endowment in songs cannot be sold but the endowed songs are available for other consumers to pirate. Endowing each music consumer with songs allows the other consumers the ability to purchase or pirate at the start of each game, rather than constraining the initial decision to always purchasing from the record label. If not all feasible strategies are available to the music consumer, we may be forcing a preference - particularly in an experiment - that could result in path dependency for future decisions.

Denote by $\alpha_{b}-1$ and $\alpha_{d}$ the respective net payoffs of buying and downloading/pirating a song at any time $t \in\{1, \ldots, T\}$. The payoffs satisfy the following assumptions: (1) $\alpha_{b}>\alpha_{d}$ : the payoff generated from consuming a purchased song is greater than the payoff generated by consuming a pirated song (for example, a pirated song may be problematic to the consumer due to viruses, poisoned content, etc); (2) $\alpha_{b}>1$ : the purchasing decision is individually rational for any consumer.; and (3) $\alpha_{d}>\alpha_{b}-1>0$ : a rational consumer will always prefer to pirate songs whenever they are available for download. In case a consumer chooses neither to buy nor to pirate a song, he earns a return of zero for that 'do nothing' decision. 
The final payoff at time $T$ for consumer $i$ is:

$$
U_{i}\left(b_{1}, \ldots, b_{n}, d_{1}, \ldots, d_{n}\right)=e+u(\bar{b})+\left(\alpha_{b}-1\right) b_{i}+\alpha_{d} d_{i}
$$

where $b_{i}$ and $d_{i}$ are the number of songs bought and pirated respectively buy consumer $i$ and $u(\bar{b})$ is the utility derived from consuming the initial endowment in songs.

The record label's profits from the consumers' purchases of songs, as well as $\alpha_{l}$ per song left in inventory. In this case, we construe $\alpha_{l}$ as representing the copyright ownership of the song. ${ }^{7}$ We impose $1>\alpha_{l}$, implying a record label would always prefer to sell a song to a consumer instead of keeping it in inventory. Thus, the record label profit is $\pi_{r}=\sum_{i=1}^{n} b_{i}+$ $\alpha_{l}\left(S-\sum_{i=1}^{n} b_{i}\right)^{8}$

As mentioned earlier, parents of the music consumers are also involved in our game. The parents are endowed with $E$ tokens. When the parent is punished for his/her child's actions, the parent suffers a loss of $\alpha_{p}$ per song pirated by the child. So, teen $i$ 's parent earns $\pi_{i}^{\text {parent }}=$ $E-\alpha_{p} d_{i}$

\section{Theoretical Predictions}

Note that the presence of parents (with or without punishment) and the record label do not change the equilibrium of a rational self-interested music consumer. So, the rest of the theoretical predictions never deals with them. To solve for the subgame perfect equilibria in our game, we use the backward induction approach. Consider the last decision, i.e, the subgame starting at decision node $M$ and assume that consumers have sufficient endowment to buy at least one song.

\footnotetext{
7 Also, from an experiment standpoint, we wanted to ensure payment to subjects representing record labels should consumers decide not to purchase at all.

${ }^{8}$ It is unclear if a particular rate of substitution of pirated goods for purchased goods should be included in the record label's utility function. The inability to reliably quantify the substitution rate has been an issue in policy debates, including the U.S. Governmental Accountability Office [51] report. Also, most industry estimates account for a range of substitution rates (e.g., the Institute for Policy Innovation [91] estimates between 20\% and 66\%; the Business Software Alliance [20] uses a one-to-one substitution rate), but most economists appear to treat piracy costs as a lack of revenue from sales.
} 
Each consumer faces a volunteer's dilemma. ${ }^{9}$ Given that the net payoff from buying $\alpha_{b}-1$ is smaller than the net payoff from pirating $\alpha_{d}$, the consumer always prefers to pirate instead of buying if at least one of other consumers buys a song, which would then be available for download by others. Note also that a consumer doing nothing is a dominated strategy in this game and so, the rest of the theoretical discussion does not deal with this strategy.

This subgame has $n$ asymmetric Pure Nash equilibria in which a single consumer buys a song. Each of these Nash equilibria are Pareto-optimal, but yield asymmetric payoffs: the consumer who buys the song gets $\alpha_{b}-1$ and the $n-1$ consumers get $\alpha_{d}$. There is also a symmetric equilibrium in mixed strategies that yield the same payoff to all players. In the symmetric equilibrium, all consumers buy with probability $p$, so the probability of getting at least one purchase decision from the $n-1$ consumers equals to $1-(1-p)^{n-1}$. The expected payoff from not buying a song is equal to $\alpha_{d}\left(1-(1-p)^{n-1}\right)+0(1-p)^{n-1}$. Equating the expected payoff from not buying to the expected payoff from buying, i.e., $\alpha_{b}-1$, the probability of pirating at decision node $M$ is given by:

$$
1-p=\left(\frac{1-\alpha_{b}+\alpha_{d}}{\alpha_{d}}\right)^{\frac{1}{n-1}}
$$

The same procedure is repeated backwards until the first decision consumers make in which they are confronted with no new songs available for download. Recall that consumers start playing with an initial endowment of songs. Therefore, at the first decision point, there are $(n-$ 1) $\bar{b}$ songs that can be downloaded. Given that pirating yields a higher net payoff than buying, the probability of pirating equals 1 for the first $(n-1) \bar{b}$ decisions. For the first $(n-1) \bar{b}$ decisions our game is basically a voluntary contribution mechanism (VCM), yielding the same

\footnotetext{
9 The volunteer's dilemma, first studied by Diekmann [41], is an n-player binary decision game in which only one player is required to make the 'sacrifice' that will benefit all the others.
} 
standard prediction of complete free-riding. ${ }^{10}$ So, for any consumer $i$ making a decision at point $m_{i}$, the probability of pirating is given by:

$$
1-p_{i}= \begin{cases}1 & \text { if } m_{i} \leq(n-1) \bar{b} \\ \left(\frac{1-\alpha_{b}+\alpha_{d}}{\alpha_{d}}\right)^{\frac{1}{n-1}} & \text { if } m_{i}>(n-1) \bar{b}\end{cases}
$$

In the experiment we consider $n=4$ consumers, each with $e=8, \bar{b}=2, \alpha_{b}=1.1$, and $\alpha_{d}=0.5$. For the record label, we set $S=32$ and $\alpha_{l}=0.1$. For the parents, $E=12$ and $\alpha_{p}=0.6$. Given these parameters the symmetric subgame perfect equilibrium of our game is:

$$
1-p_{i}= \begin{cases}1 & \text { if } m_{i} \leq 6 \\ 0.9283 & \text { if } m_{i}>6\end{cases}
$$

Given that we are interested in understanding how well advice can dissuade piracy, we intentionally chose parameters wherein the pirating probability is quite high in the Nash equilibrium.

\section{$\underline{\text { Treatment Design and Hypotheses }}$}

The previous section presented the equilibrium analysis when there was no communication (advice) sent to the consumers. Our interest in the paper is to study the effects of the source of advice on pirating and purchasing behavior. To do so, as we will detail later, we conduct an experiment of the same game over multiple iterations. Subsequently, after every few iterations, advice is provided depending on the treatment and the outcomes which are to be analyzed. The experimental treatments section details how the various treatments, i.e., the sources of advice, are different. Following that, the behavioral hypotheses section provides the hypotheses regarding the implications.

\section{Experimental Treatments}

\footnotetext{
${ }^{10}$ Note that as compared to the standard VCM, our game has a different marginal return from player's own contribution as compared to the marginal return from the contributions of others. Also, the consumption of the public good is not binding.
} 
We consider four experimental treatments which differ in the source of advice. Within each source of advice our treatments vary along two dimensions. The first dimension is whether a social tie exists between the advisor and advisee. The second dimension is whether the source of advice has a stake in the outcome of the consumers’ purchasing and pirating decisions. Table 1 represents the four treatments in a $2 \times 2$ matrix. We expand below on how the dimensions are varied in each of the treatments, and how the treatments reflect the educational approach pursued by stakeholders in digital goods industries.

\section{[Insert Table 1 about here]}

We first consider the presence of a social tie between the advisor and the advisee. An appropriate representation of the social tie dimension in our piracy context are the parents of the music consumers. Parents are often targeted as the source of advice when using an educational approach to combat piracy $[83,87]$. Also, parents are in a position of authority and control over their teens, and the teens’ perception of advice represents this relationship [61, 62]. We consider two treatment variants involving parents to allow us to capture the possible reality of losses due to litigation, and therefore the stake in the game dimension. One variant where parents incur no punishment because of their child's (consumers') actions, and another variant where parents incur a punishment.

In contrast, we also consider advice coming from a record label or an industry regulator. Both sources again allow us to represent the educational approach to combating piracy when there is no social tie with the consumer, while varying the stake in the game dimension. The record label has a stake in the game, i.e., the pirating / purchasing decision impacts its profits, and is motivated from news articles involving recording artists advising against piracy (e.g., Metallica [65]). However, the regulator does not have a direct and immediate stake in the game. 
When an action is taken by a regulator that generates attention about piracy, it may be construed as advice. For example, the SOPA and PIPA legislative proposals from the U.S. Congress brought to prominence the negative impact of piracy [92, 104].

\section{Behavioral Hypotheses}

The theoretical game predictions presented in the game and theoretical predictions section assume that the consumers' utility is exclusively dependent on their monetary payoff. In this section, in order to derive behavioral hypotheses, we consider a more general utility function given by:

$$
\widehat{U}_{i}=U_{i}+\beta_{i j} \pi_{j}+\gamma_{i j}
$$

where $U_{i}$ is the monetary payoff earned by consumer $i$ as defined previously in Equation $1, \pi_{j}$ is player $j$ 'smonetary payoff as defined previously in the piracy game section, and where $j=$ $R L, R E G$, Parent. ${ }^{11}$ Consider $\beta_{i j}$ as the weight consumer $i$ puts on player $j$ 's monetary payoff. In addition to caring for monetary payoffs, consumer $i$ may also face a loss of utility $\gamma_{i j}$ from neglecting player $j$ 's advice. We assume $\beta_{i j} \geq 0$ and $\gamma_{i j} \leq 0$.

First, assume consumers have standard preferences, i.e., they are rational, with no moral impediments, and are selfish. In this case, regardless of advisors and/or other players having a direct stake in the game, their incentives are never aligned with that of the consumer, i.e., $\beta_{i j}=$ 0. Moreover, consider those consumers that do not face any utility loss from neglecting others’ advice $\left(\gamma_{i j}=0\right)$. The advice is then merely considered as cheap talk and has no effect on consumers' behavior [34]. So, the standard predictions from the game and theoretical predictions section become applicable independent of the treatments. Formally,

Hypothesis 1a: According to standard preferences, the advice is cheap talk and will make

\footnotetext{
${ }^{11}$ The additive form and the assumption that $j$ excludes other consumers are for simplification. REG never earns a payoff, however REG can be
} 
no difference in the number of songs pirated (purchased) and the probability of pirating in any treatment. ${ }^{12}$

Hypothesis 1b: According to standard preferences, the level of piracy (purchases) should be the same in all four treatments.

Next, assume that consumers have outcome-oriented social preferences, i.e., they are not selfish and care for the earnings of other subjects $\left(\beta_{i j}>0\right)$. This is consistent with the theoretical models of Fehr and Schmidt [46] and Bolton and Ockenfels [17], as well as experimental evidence from Croson [36] and Fehr and Gächter [45]. While still retaining the assumption that advice is merely considered cheap talk $\left(\gamma_{i j}=0\right)$, consumers care for the earnings of other subjects with a stake in the game and adjust their behavior accordingly. Therefore, we should observe more purchases, and consequently lower levels of piracy than predicted by standard theory. Specifically, the record label has a stake in the game and is affected by the number of songs purchased in all treatments. Moreover, in the presence of outcome-oriented social preferences, given that both the record label and the parent have a stake in the game, the level of piracy in the $P P$ treatment should be the lowest compared to the other treatments. The following hypotheses formalize the predictions in those cases where consumers are motivated by outcome-oriented social preferences.

Hypothesis 2a: According to outcome-oriented social preferences, the advice is cheap talk and will make no difference in the number of songs pirated (purchased) and the probability of pirating in any treatment.

Hypothesis 2b: According to outcome-oriented social preferences, the level of piracy (purchases) should be lower (higher) in the $P P$ treatment as compared to the other three

${ }^{12}$ Recall that 'doing nothing' is a dominated strategy. If consumers pirate less, then they purchase more, and vice-versa. 
treatments. The level of piracy (purchases) should be the same in the $P N P, R L$, and $R E G$ treatments, but lower (higher) than standard predictions.

Now let consumers face a utility loss from not following advice, i.e., $\gamma_{i j}<0$. This may indeed be the case if consumers believe others' expect a particular behavior from them, as they may feel shame or guilt from letting them down. These behaviors have been theoretically presented in the literature, e.g., Battigalli and Dufwenberg [10, 11], as well as shown experimentally in Charness and Dufwenberg [23], and Ellingsen et al. [43]. ${ }^{13}$ Formally,

Hypothesis 3: If consumers bear a utility loss from not following advice, the level of piracy (purchases) should be lower (higher) after the advice is given.

The feelings of shame and guilt from not following advice are very likely to depend on with whom consumers interact. More specifically, not only may the advice impact behavior, but the source of advice may affect the intensity of that behavior. Regarding the source of advice, our experiment focuses on two dimensions: stakes and social ties. Consider first the social ties. As social ties are often formed unconsciously through social interactions [33], the social tie with a parent is expected to be stronger than a social tie with a record label or with the regulator. Moreover, social psychologists have claimed that the attitudes toward entities for which there is a social tie are more favored by individuals over those for which there is not a social tie [42]. Consequently, letting parents' expectations down by not following their advice may cause consumers to feel guilty and/or ashamed when compared to not meeting either the record label's, or the regulator's expectations by not following their advice.

Lastly, consider whether the advisor has a stake in the game. Even if consumers follow advice in order to meet the expectations of the advisor, the effect of advice is likely to be

\footnotetext{
${ }^{13}$ Note that in this section we make qualitative behavioral predictions in order to better understand our results. Our aim in this experiment is to get a clear effect of advice on behavior and not to measure feelings of shame and guilt from not following advice. Otherwise, we would have
} 
stronger if the advisor has a stake in the game. Therefore, in our experiment, we expect the advice from the record label to lead to more purchasing and less pirating. In a similar vein, the advice from the parents with stakes in the game should lead to more purchasing and less pirating also. Note that if the advisor has a stake in the game, the advice is more likely to be followed and this likelihood is higher with the existence of social ties between the advisor and the advisee. The aforementioned arguments are formalized as follows:

Hypothesis 4a: The effect of advice is stronger if there is a social tie between the advisor and the advisee. The level of piracy (purchases) should be lower (higher) in the $P P$ and PNP treatments as compared to the other two treatments.

Hypothesis $4 b$ : The effect of advice is stronger if the advisor has a stake in the game. The level of piracy (purchases) should be lower (higher) in the $P P$ and $R L$ treatments as compared to the other treatments.

Hypothesis 4c: The decrease (increase) in pirating (purchasing) behavior because of the increased stake of the advisor will increase with the existence of the social tie.

In summary, whenever advice is considered to be cheap talk, we should observe no difference in behavior after advice is given. Therefore, even though the level of piracy is expected to be lower in the case of outcome-oriented social preferences, neither the advice nor its source accounts for the behavior. The advice, however, is not cheap talk if consumers face a utility loss from neglecting it. In that case, the characteristics of the advisor may also play a role in how advice is taken into consideration. Moreover, consumers might feel shame if they believe others' expect them to not engage in piracy activities, or may feel guilt from letting others down by engaging in such behavior. These effects may further reduce piracy behavior across

needed to elicit second order beliefs from the consumers, i.e., their own beliefs about the beliefs of advisors regarding their willingness to follow advice, which could have influenced reactions to the advice. 
treatments. ${ }^{14}$ Moreover, feelings of shame and guilt from doing something wrong can be strengthened by the existence of advice. On one hand, music consumers know that advisors are informed, from time to time, about the consumers' behavior. On the other hand, the advice can make the expectations more salient about a certain behavior to follow. Each of these arguments further strengthen hypotheses 4a-4c.

\section{Experiment Implementation}

Experiments were conducted such that each subject was allowed to participate in only one session. Every participant was assigned to the same group for the entire session, and each session involved at least 2 groups. Consistent with the game setup, four music consumers $(n=4)$ and one record label were part of one group. In treatments where parents provided the advice, the corresponding parent or guardian was assigned to the same group. The groups were created such that, other than their own parent (or guardian), subjects did not know the identity of their group members. We did so to minimize reputation effects. In each session, only one experimental treatment was considered, and each session involved 20 rounds of the Piracy Game being played.

\section{[Insert Table 2 about here]}

Table 2 provides the details about the experimental parameters. In each round, every music consumer is endowed with $e=8$ tokens and $\bar{b}=2$ songs. The music consumer earns $\alpha_{d}=$ 0.5 tokens for each song pirated. If the music consumer instead chooses to purchase a song from the record label, 1 token is spent for the song, earning $\alpha_{b}=1.1$ tokens. The net gain to the music consumer is therefore $\left(\alpha_{b}-1\right)=0.1$ tokens per purchased song. We normalize $u(\bar{b})$ to be zero in our setting. Explicitly accounting for the endowed song would have forced us to impose assumptions onto the music consumer about the type of song (whether pirated or

\footnotetext{
${ }^{14}$ Consumers may also face an intrinsic moral cost from engaging in piracy. If consumers dislike engaging in piracy, the level of piracy (purchases) should be the same in all treatments, but lower (higher) than standard predictions.
} 
purchased). In doing so, we might prime the decision-making process of the music consumer. Moreover, setting $u(\bar{b})=0$ does not theoretically change the comparative statics of the various treatments because the payoff from the endowed songs is functionally separable in Equation 3.

The record label is endowed with $S=32$ songs, earns 1 token for each song sold, and also receives $\alpha_{l}=0.1$ tokens per unsold song left in their inventory each round. The endowment was set to 32 because it is the maximum the record label will sell given that 4 music consumers exist in a group, each with 8 tokens at the beginning of each round.

In the treatments involving parents, they receive an endowment of $E=12$ tokens. If a music consumer pirates, the corresponding parent incurs a loss of $\alpha_{p}=0.6$ tokens per pirated song in the $P P$ treatment.

For each session, we may not be able to finish conducting the desired number of rounds without a time limit as subjects may simply wait for their peers to purchase songs before they take any action. To avoid such scenarios, subjects are given $T=25$ seconds within each round to make as many purchase / pirate / do nothing decisions they would like to make. We decided on this limit after several pilot sessions. We also based it on the $P P$ treatment because we do not want to allow the potential earnings for parents to go negative (i.e., $12-0.6 * 20=0$ ).

The aforementioned steps are repeated for each of the 20 rounds. Twice during the 20 rounds of play, we facilitate communication of advice to the consumers, with the source of advice depending on the treatment. The source of advice for each treatment was always made known to all subjects prior to starting the experiment. They did not know ex ante when they would receive advice, only that they would at some point receive advice from their parent, the record label, or the experiment administrator (taking the role of the regulator). The advice is given for the first time after the $8^{\text {th }}$ round, and after the $14^{\text {th }}$ round for the second time. This design allows us to 
separate the rounds into three blocks. The first block includes 8 rounds where no advice is provided and two other blocks each of 6 rounds of length after the advice is provided.

If the treatment designates the advice is to be given by the record label or experiment administrator, the advice is sent via the computer screen. If the treatment involved advice from the consumer's parent, the advice is handwritten on paper by the parent, then handed to the consumer by the experiment administrator. Although handwriting the parent's advice creates additional time spent and organizational challenges, using this approach reinforces the consumer's belief that the advice is truthfully from the parent, a critical feature of our design. We do not believe that the difference in the medium of communication (via paper versus via computer screen) creates a difference in the outcomes. Prior experimental literature and, in particular, the public goods related work has considered the impact of the medium of communication on coordination, but did not find a difference on average between various types of non-verbal communication (e.g., Brosig et al. [19]). Regardless of the source of advice, the wording and content of the advice was similar across all sources. Whenever the advice was delivered, it always contained information about the record label's earnings and average amount of piracy occurring among the group members. At the start of round 9, only that information is provided as advice. At the start of round 15 , the advice that consumers received also included the moral opinion of the source (i.e., parent, record label, regulator) about piracy - specifically, “morally acceptable,” "morally wrong," "strongly believe it is morally wrong."

We conducted the experiment in the Vernon Smith Experimental Economics Laboratory at Purdue University during the summer and fall of $2011-2012 .^{15}$ In treatments involving parents, subjects were recruited by visiting new student orientation sessions having both parents and

\footnotetext{
15 The lab is constructed with partitioned desks for each subject, and has 28 computers with flat-panel displays, plus one administrator server computer. There is an observation room with one-way glass adjacent to the laboratory and is used to monitor subject behavior throughout the
} 
students, making a verbal announcement to the audience, and asking for voluntary participation. In other treatments, subjects were recruited by email using the laboratory's online recruitment system. A total of 123 subjects participated in our experimental sessions (PNP: 20 music consumers, 20 parents, 5 record labels; PP: 8 music consumers, 8 parents, 2 record labels; REG: 24 music consumers, 6 record labels; $R L$ : 24 music consumers, 6 record labels). The experiment was computerized using the z-Tree v.3.3.6 software package [47]. Upon entering the laboratory, subjects were randomly assigned to individual computers and communication between subjects was not allowed during the session. Experiment instructions were provided to each subject and were read aloud by the experiment administrator. A copy of the instructions is available in the Appendix. We randomly chose three of the twenty periods for payment, and paid each subject their total profit over these periods at a conversion rate of 0.8 tokens per US dollar. Using this approach avoids wealth effects because the earnings from each round are valued independently of each other, reducing the ability for wealth to encourage manipulation of later rounds. The experiment lasted on average 1 hour and subjects were compensated $\$ 12.05$ on average. We concluded each session with a short demographic questionnaire, and all subjects were paid in cash privately and individually.

\section{Experimental Results}

This section presents the experimental data and tests for our hypotheses. ${ }^{16}$ The first subsection compares piracy decisions to the theoretical prediction of our game. Next, we analyze the aggregate results of pirating and purchasing behavior across treatments. Finally, the short-term and lasting effects of advice are discussed.

experiment.

16 Note that our data are not conducive to evaluate the "shock" value of advice from various sources. At the beginning of the experiment, the subjects are informed in the instructions that they will receive advice at times from a particular source (i.e., parent, record label, or regulator). In other words, the subjects' behaviors in the initial rounds are subject to that information already. It means that the reference we have to compare across the treatments is not consistent. Therefore, instead of comparing the shock value of advice, we focus on the source of advice as a whole 
We note the following two remarks: First, for the analysis, we use only non-parametric tests to compare treatments. The use of relatively simple statistics are common in experimental economics studies, including those in leading economic outlets (see e.g., Andersen et al. [5], Kosfeld et al. [68]). Such an approach is sufficient because experiments - particularly those conducted in the lab - carefully control for possible confounding effects by having a random assignment of participants. Second, and unless explicitly stated otherwise, we omit the first eight rounds of the game from the analysis. We do so to focus on treatment differences after the advice is given, and to allow subjects to learn the technology used to conduct the experiment. Therefore, rounds 9-20 are analyzed in two blocks of six rounds each, i.e., 9-14, and 15-20, accounting for the provision of advice at the beginning of the $9^{\text {th }}$ and $15^{\text {th }}$ rounds.

\section{Clickstream Data and Nash Equilibrium}

[Insert Figure 1 about here]

We first investigate whether consumers follow the Nash equilibrium predictions. Recall the implementation of our experiment captures clickstream data for each pirating and purchasing decision made by the consumers during the game. Note that although a 'do nothing' option was also provided in addition to purchasing or pirating songs, we did not observe the 'do nothing' decision being taken in our data. Figure 1 presents a comparison of the decisions in each consumers' clickstream over rounds 9-20. The horizontal axis represents the clickstream of piracy decisions within each round, while the vertical axis shows the percentage of consumers choosing to pirate at a particular point in time during the clickstream. The Nash prediction is shown at the top of the figure. In the predicted line, the $7^{\text {th }}$ decision represents the point during the round where there are no additional songs left to pirate. Therefore, the equilibrium prediction equals to $100 \%$ of piracy until click 7 , and $92.83 \%$ from click 7 onwards. Each treatment is 
plotted as well.

We observe consumers in all treatments pirating below the equilibrium level. In particular, the $P P$ treatment begins at a much lower percentage of piracy in comparison with the others. Over time the consumers in this treatment begin to pirate more, eventually approaching the levels of piracy of other treatments. Despite the piracy levels being below the Nash predictions, there is a similar trend in decision-making at the $7^{\text {th }}$ decision in the clickstream. In particular, we observe the consumers slightly reducing their pirating at that time, followed by an oscillating cycle of increasing and decreasing piracy. The clickstream analysis shows that consumers do not fully behave as standard theory predicts, giving a first indication that hypothesis $1 \mathrm{~b}$ does not hold.

\section{Pirating and Purchasing Behavior Across Treatments}

[Insert Figure 2 about here]

Figure 2 gives a general perspective of the patterns of pirating and purchasing decisions. Sub-figure (a) plots the average number of pirated songs, and sub-figure (b) plots the average number of purchased songs in each round for each treatment. Recall that advice is given twice, first after round 8 and, again, after round 14. Three main observations emerge from the figures:

First, consumers follow a similar pattern of pirating and purchasing in each of the treatments (several notable differences are examined later in the next section). More specifically, in each treatment, there is an increasing trend in pirating behavior until round 9, where the behavior in each of the treatments levels off and, in some circumstances, begins to oscillate up and down. In contrast, purchasing behavior tends to be relatively flat across all the rounds in all the treatments.

Second, consumers seem to respond to advice by decreasing their pirating behavior for a short while, which is shown by the dip in average number of pirated songs after rounds 8 and 14 . 
Two exceptions are however observed. A few rounds after receiving the advice, consumers seem to disregard the advice in the REG treatment, as shown by the large increases in downloading after round 9. Also, the downloading increases slightly for the $R L$ treatment in round 15 compared to round 14. Regarding purchasing behavior, there is a slight increase after advice in all of the treatments. In particular, the PNP treatment shows a large increase in purchasing after the last round of advice. The effect of advice is further discussed in the next section.

Finally, there are some differences across treatments in the number of songs pirated and purchased. In particular, the number of pirated songs is lower and the number of purchased songs is higher in the $P P$ treatment as compared to the other treatments. Next, we explore in more detail the differences in pirating and purchasing behavior across treatments at an aggregate level, investigating whether social ties and/or having a stake in the game can possibly explain differences across treatments.

\section{[Insert Table 3 about here]}

Table 3 presents aggregate results for the last two blocks of rounds, each after the provision of advice. As can be seen, the $P P$ treatment shows less pirating and more purchasing in comparison to the other treatments. Consumers, therefore, appear to internalize the penalty suffered by parents, restricting their piracy behavior and purchasing more often, even if this reduces their own earnings. All of the pairwise comparisons between the $P P$ treatment and every other treatment are significantly different for both purchasing and pirating levels using a Mann-Whitney rank-sum $U$-test for rounds 9-14, with the exception of the comparisons with $P N P$ and $R L$ for pirating in rounds $15-20 .{ }^{17}$

\footnotetext{
${ }^{17}$ Rounds 9-14, comparison of purchases: $P P$ vs. $P N P, z=3.16, p<0.01 ; P P$ vs. $R L, z=4.42, p<0.01 ; P P$ vs. $R E G, z=3.86, p<$ 0.01 ; Rounds 9-14, comparison of pirating: $P P$ vs. $P N P, z=-2.33, p=0.02 ; P P$ vs. $R L, z=-2.11, p=0.03 ; P P$ vs. $R E G, z=-3.67$, $p<0.01$; Rounds 15-20, comparison of purchases: $P P$ vs. $P N P, z=1.89, p=0.06$; $P P$ vs. $R L, z=3.38, p<0.01 ; P P$ vs. $R E G, z=2.86$, $p<0.01$; Rounds 15-20, comparison of pirating: $P P$ vs. $P N P, z=-0.72, p=0.47 ; P P$ vs. $R L, z=-0.92, p=0.36$; $P P$ vs. $R E G, z=$ $-2.48, p=0.01$.
} 
These results indicate that subjects are not fully selfish and seem to care about the outcome of others, in particular the outcome of their parents. However, consumers do not seem to be motivated solely by outcome-oriented preferences, otherwise we should observe no significant differences across the other three treatments, providing partial evidence in support of hypothesis $2 b$. Indeed, this is not the case as we can see next.

First, results from the $R E G$ treatment show a statistically significant and higher level of piracy than the one observed in all the other treatments for both rounds 9-14 and rounds $15-20 .{ }^{18}$ Second, there are statistically significant differences between the PNP treatment and the $R L$ treatment for purchases in the two blocks of rounds. ${ }^{19}$. Finally, and the most striking result, the $R L$ treatment shows the worst average profit outcome in comparison to the others. The result highlights the risk of a digital goods producer engaging in anti-piracy messaging. The main reason behind this result is that fewer songs are being purchased in comparison with other treatments.

All of the differences across treatments seem to indicate that, besides having potential outcome-oriented social preferences, consumers seem to care about the advice. More specifically, and as stated in the behavioral hypotheses section, consumers may feel shame or guilt for not fulfilling others' expectations. This indicates that hypothesis $1 a$ and hypothesis $2 a$ do not hold. Therefore, we find evidence for hypothesis 3, i.e., that advice might not be cheap talk, which is further developed in the short-term and lasting effects section.

Despite an initial belief that teens engage in a "purposeful flight away,” parents do in fact matter, especially so when parents are punished for the teens' behavior. Moreover, given that

\footnotetext{
18 The Mann-Whitney rank-sum $U$-tests are: Rounds 9-14, comparison of purchases: $P P$ vs. $R E G, z=3.86, p<0.01 ; P N P$ vs. $R E G, z=$ 1.53, $p=0.13$; $R L$ vs. $R E G, z=-0.19, p=0.85$. Rounds $9-14$, comparison of pirating: $P P$ vs. $R E G, z=-3.67, p<0.01 ; P N P$ vs. REG, $z=-3.68, p<0.01 ; R L$ vs. $R E G, z=-5.34, p<0.01$. Rounds $15-20$, comparison of purchases: $P P$ vs. $R E G, z=2.86, p<0.01 ; P N P$ vs. $R E G, z=1.56, p=0.12$; $R L$ vs. $R E G, z=-0.31, p=0.76$. Rounds $15-20$, comparison of pirating: $P P$ vs. $R E G, z=-2.48, p=0.01$; $P N P$ vs. $R E G, z=-3.32, p<0.01 ; R L$ vs. $R E G, z=-5.22, p<0.01$.
} 
consumers knew from the beginning of the experiment that a message would be received, they might have acted in order not to let their advisor down. If that is the case, and as discussed in the behavioral hypotheses section, social ties and having a stake in the game are two mechanisms that can potentially explain the differences we found across treatments. Next, we consider the impact of social ties on purchasing and pirating behavior.

\section{The Role of Social Ties}

\section{[Insert Table 4 about here]}

Recall that hypothesis $4 a$ states that the effect of advice is stronger if there is a social tie, which will result in less pirating and greater purchasing by the consumer. Table 4 provides results aggregated along the dimension of social ties, grouped by each block of rounds. We can clearly see a pattern where the existence of a social tie results in greater purchases, less piracy, and greater profit for the record label. The noted patterns in the results are confirmed to be statistically significant between treatments using Mann-Whitney rank-sum $U$-tests. ${ }^{20}$ Overall, we find support for hypothesis $4 a$. As before, it appears that parents do matter.

\section{The Role of having a Stake in the Outcome of the Game}

\section{[Insert Table 5 about here]}

Recall that hypothesis $4 b$ states that the effect of advice is stronger if the advisor has a stake in the game, which will result in less pirating and greater purchasing by the consumer. Table 5 aggregates results for those treatments with and without a stake in the outcome, organized by blocks of rounds. We observe statistically significant differences between the grouped treatments for pirated songs only. The amount of purchased songs remains indistinguishable whether or not

\footnotetext{
19 The Mann-Whitney rank-sum $U$-tests are: Rounds 9-14, comparison of purchases: $P N P$ vs. $R L, z=1.93, p=0.05$; Rounds $15-20$, comparison of purchases: $P N P$ vs. $R L, z=2.31, p=0.02$.

${ }^{20}$ Rounds 9-14, comparison of purchases: Social Tie vs. No Social Tie, $z=-3.60, p<0.01$. Rounds 9-14, comparison of pirated songs: Social Tie vs. No Social Tie, $z=2.67, p<0.01$. Rounds 15-20, comparison of purchases: Social Tie vs. No Social Tie, $z=-3.29$, $p<0.01$. Rounds 15-20, comparison of pirated songs: Social Tie vs. No Social Tie, $z=2.37, p=0.02$.
} 
the advisor has a stake in the outcome. It appears that when a stake is involved, consumers are less willing to harm the utility of others when it comes to pirating songs. At the same time, consumers are not more willing to hurt their own utility by purchasing songs in excess of when a source of advice does not have a stake in the outcome. As before, the results are confirmed to be statistically significant between treatments using Mann-Whitney rank-sum $U$-tests. ${ }^{21}$ Thus we find partial support of hypothesis $4 b$ for pirating but not for purchasing. Consequently, from the record label's standpoint, the profits are also the same.

\section{The Interaction of Social Ties and Stake: Difference-in-Difference Measure}

Another interesting analysis is how the stake of the advisor plays out with and without social ties. Therefore, we compute the difference of the average purchases/downloads between the $P P$ and PNP treatments, giving us a measure of the impact of having a stake in the outcome when there is a social tie. Similarly, we compute the difference of the average purchases/downloads between the $R L$ and $R E G$ treatments, giving us a difference measure of the averages of the stake in the outcome when there is no social tie. Then, we take the difference of the differences. Results are aggregated to rounds 9-20 and presented in Table 6. In the case of purchases, the difference-in-difference measure results in a test statistic of $t=4.25$, which is statistically significant at $p<0.01$. In the case of pirating songs, the difference-in-difference measure results in a test statistic of $t=0.87$, which is not statistically significant. Our result provides partial support for hypothesis $4 c$.

[Insert Table 6 about here]

\section{The Short-term and Lasting Effects of Advice}

Next we look at the longevity of the effect of advice. Table 7 presents analyses of immediate and

${ }^{21}$ Rounds 9-14, comparison of purchases: Stake vs. No Stake, $z=-0.62, p=0.53$. Rounds 9-14, comparison of pirated songs: Stake vs. No Stake, $z=4.49, p<0.01$. Rounds 15-20, comparison of purchases: Stake vs. No Stake, $z=0.11, p=0.91$. Rounds $15-20$, comparison of 
lasting effects of advice for each treatment. The treatments are organized by blocks of rounds, with the upper rows representing the effect of advice over the second block of rounds, and the lower rows representing the effect of advice over the third block of rounds. The upper block of rows in Table 7 defines immediate effects as the comparison of rounds 6-8 with 9-11, and lasting effects as the comparison of rounds $6-8$ with $12-14$. The lower block of rows in Table 7 defines immediate effects as the comparison of rounds $12-14$ with 15-17, and lasting effects as the comparison of rounds $12-14$ with 18-20.

\section{[Insert Table 7 about here]}

The values in each of the columns show the difference between the means (i.e., before advice minus after advice), and the Wilcoxon signed-rank test $z$-statistic. A negative sign on a value indicates that purchasing (pirating) increases after advice, whereas a positive sign indicates purchasing (pirating) decreases after advice. As can be seen from the table, we find the following differences to be statistically significant. Advice in $P N P$ has an immediate effect of increased purchasing in both blocks of rounds. PNP also has a marginally significant immediate effect of decreased pirating in the third block of rounds. Advice from the $R E G$ treatment never has an immediate or lasting effect on piracy behavior and is perceived simply as cheap talk by the subjects. REG only shows a marginally significant immediate decrease in purchasing behavior in the second block of rounds. The results indicate partial support for hypothesis 3 when there is a social tie and no stake in the outcome, by increased purchasing after advice in the PNP treatment.

We do not observe any immediate effects of advice for the treatments with a stake in the outcome. Subjects may have already accounted for their guilt-averse preferences without needing to receive advice, thus hypothesis 3 does not hold for treatments when there is a stake in the 
outcome, regardless of social tie. The $R L$ treatment even shows a lasting effect of increased pirating across the second and third block of rounds. A few curious results also emerge from the $P P$ treatment in the lasting effects for both purchasing and pirating across both blocks of rounds. In the second block of rounds, advice has a lasting effect of marginally increased piracy. In the third block, the advice has a lasting effect on behavior as shown by decreased purchasing and increased pirating. A probable explanation for the teens' behavior in $P P$ is that they tire of accounting for their parent's punishment, and would rather attempt to maximize their payoff as possible end-of-game effects.

\section{Summary of Results}

Overall, our results provide many interesting insights into the relationship between advisors and advisees when it comes to using advice to influence purchasing and pirating behavior. Across all of our analyses, it is broadly clear that having a social tie has a strong influence on purchasing behavior, but less so on influencing pirating behavior. With regard to the stake in the game, it is critically important for the adviser to have both a stake in the game and a social tie with the advisee, illustrated by the $P P$ treatment. The relationship between an increasing stake and increasing social tie to the consumer is also critical, otherwise the advice is viewed as cheap talk and completely disregarded. Ultimately, the $P P$ treatment is the most effective at both decreased pirating as well as increased purchasing among all of the treatments.

\section{Discussion and Conclusion}

Digital piracy has been drawing significant attention from both policy makers and digital goods producers. To thwart piracy, producers have been pursuing both direct and indirect nudging strategies. Ex ante it is not clear if either strategy is effective. On one hand, the target population may not heed to advice directly from record labels because the advice may be considered as 
self-fulfilling. Also, indirect advising via parents may not work because the target population is engaged in a "purposeful flight away" from their parents. Moreover, prior work thus far does not appear to have formally analyzed the implication of the various nudging strategies. With the aim of filling this gap, our paper investigates the implications of the source of advice on pirating as well as purchasing decisions.

For our analysis, we conduct experiments using a variant of the volunteer's dilemma game. Our Piracy Game is distinctive in the sense it explicitly accounts for the difference between pirating and purchasing decisions. Subjects in our experiments were subjected to one of four treatments that differ in terms of the source of advice. These treatments vary along two dimensions - one is whether the source of advice has a social tie with the subjects, and the other is whether the advisor has a stake in the outcome of the game. Our implementation of the game also allows us to conduct a clickstream analysis, another aspect not common in many behavioral economics studies.

Our experimental data identified several insights, of which some are as follows. When there is a tangible stake for the parent for their teens' actions (e.g., potential litigation), purchasing behavior by the teen is significantly increased, and pirating behavior is slightly decreased. Even when there is not a stake for the parents , the advice is most effective when the advisor has a social tie (parent as opposed to the record label or a regulator). These results indicate that regulators and record labels should perhaps enhance their focus on education channels through advisors with a social tie to the pirates, by reaching out to parents, guardians, and other close or important sources of advice to the teens. On the contrary, when the record label provides advice, the profit generated surprisingly results in the worst outcome. This result represents the finding that music consumers are undeterred by the direct complaints from the music industry and - for 
better or for worse - it appears our results may in fact capture populist sentiment (e.g., negative sentiments towards Metallica and their stance on piracy [65]). Although the industry is attempting to shift to education strategies (e.g., [84, 87, 88, 89, 93]) in lieu of litigation (or technology controls for that matter), the current status quo of sending advice directly from third parties could certainly be improved by coordinating advice through channels with social ties to the pirates. ${ }^{22}$

Our results contribute to the body of knowledge in various streams. The question about which should be the source of advice to shape piracy behavior does not appear to have been considered in the piracy literature thus far. Our result that advice from parents matters might be surprising because the target population appears to be on a "purposeful flight away" from parents. However, that result is consistent with Allen and Land [4]. Our empirical comparisons across the various sources of advice are new to the developmental psychology literature. The formal consideration of a social tie in the context of unilateral communication (i.e., advice) is also a contribution to the cheap talk and social ties literature in economics.

While we believe that our paper provides actionable insights, it is not without limitations and opportunities for future research. In order to be parsimonious in terms of design in a lab setting, we assumed consumers made purchased music automatically available for others to pirate. Nevertheless, relaxing that assumption is an important future research question worth considering, both from an experimental as well as a practical standpoint. Also, in this study, we only analyzed the existence of a social tie but not the degree. Varying the quality of the social tie between subjects may be worth considering and could be explored as a future study to develop additional insights. Explicitly accounting for pro-social behavioral dimensions such as shame and guilt may also be explored to better understand the incorporation of these factors in the

\footnotetext{
${ }^{22}$ On a related note, we conducted experiments with friends as sources of advice and observed qualitatively similar results as parents.
} 
decision to purchase or pirate. A future study might also pursue this topic using field

experiments. Lastly, given that responses to advice differ depending on factors such as whether

the advice is solicited or not, whether advice is from a social perspective or from an individual

perspective, etc. (e.g., McDowell et al. [75]), future research could consider exploring the

effectiveness of combining advice with another mechanism (e.g., parental support, parental

influence, monitoring of behavior, instituting consequences, modifying beliefs) to shape piracy

behavior.

\section{References}

1. 2D Boy. 90\%. (2008) (http://www.2dboy.com/category/uncategorized/page/10/, accessed September 19, 2010).

2. Abbink, K., Irlenbusch, B., and Renner, E. Group size and social ties in microfinance institutions. Economic Inquiry, 44, 4 (2006), 614-628.

3. Ahn, T., Isaac, M., and Salmon, T. Endogenous group formation. Journal of Public Economic Theory, 10 (2010), 171-194.

4. Allen, J., and Land, D. Attachment in adolescence. In Cassidy, J. and Barnett, N., (eds.), Handbook of attachment: Theory, research, and clinical applications. New York: Guilford Press, 1999, pp. 319-335.

5. Andersen, S., Ertaç, S., Gneezy, U., Hoffman, M., and List, J. Stakes matter in ultimatum games. American Economic Review, 101, 7 (December 2011), 3427-3439.

6. Anderson, L. Public choice as an experimental science. In Shughart, W. and Razzolini, L. (eds.), The Elgar companion to Public Choice. Cheltenham Glos:Elgar, 1995, pp. 497-511.

7. Andreoni, J., Harbaugh, W., and Vesterlund, L. The carrot or the stick: Rewards, punishments, and cooperation. American Economic Review, 93 (2003), 893-902.

8. Andreoni, J. An experimental test of the public-goods crowding-out hypothesis. American Economic Review, 83 (1993), 1317-1327.

9. Barnes, G. Adolescent alcohol abuse and other problem behaviors: Their relationships and common parental influences. Journal of Youth and Adolescence, 13, 4 (1984), 329-348.

10. Battigalli, P., and Dufwenberg, M. Guilt in games. American Economic Review 97, 2 (2007), 170-176.

11. Battigalli, P., and Dufwenberg, M. Dynamic psychological games. Journal of Economic Theory 144, 1 (2009), 1-35.

12. Ben-Ner, A., and Putterman, L. Trust, communication, and contracts: An experiment. Journal of Economic Behavior \& Organization, 70 (2009), 106-121.

13. Bhattacharjee, S., Gopal, R., Lertwachara, K., and Marsden, J. Consumer search and retailer strategies in the presence of online music sharing. Journal of Management Information Systems, 23, 1 (Summer 2006), 129-159.

14. Bhattacharjee, S., Gopal, R., Marsden, J., Sankaranarayanan, R., and Telang, R. To theme or not to theme: Can theme strength be the music industry's "killer app"? Decision Support Systems, 48, 1 (2009), 141-149. 
15. Bhattacharjee, S., Gopal, R., and Sanders, G. Digital music and online sharing: Software piracy 2.0? Communications of the ACM, 46, 7 (2003), 107-111.

16. Bochet, O., Page, T., and Putterman, L. Communication and punishment in voluntary contribution experiments. Journal of Economic Behavior and Organization, 60 (2006), 11-26. 17. Bolton, G., and Ockenfels, A. Erc: A theory of equity, reciprocity, and competition. American Economic Review 90, 1 (March 2000), 166-193.

18. Borsari, B., Murphy, J., and Barnett, N. Predictors of alcohol use during the first year of college: Implications for prevention. Addictive Behaviors, 32 (2007), 2062-2086.

19. Brosig, J., J.Weimann, and A. Ockenfels (2003). The effect of communication media on cooperation. German Economic Review, 4, (2) 217-241.

20. BSA. Seventh annual bsa/idc global software: 09 piracy study. Business Software Alliance, 2010.

21. Cason, T., and Khan, F. A laboratory study of voluntary public goods provision with imperfect monitoring and communication. Journal of Development Economics, 58 (1999), 533-552.

22. Chakravarty, S., Ma, Y., and Maximiano, S. Lying and friendship. Working Paper, (2012). 23. Charness, G., and Dufwenberg, M. Promises and partnership. Econometrica, 74, 6 (November 2006), 1579-1601.

24. Charness, G., and Yang, C. Public goods provision with voting for exclusion, exit, and mergers: An experiment. Working Paper, (September 22, 2010).

25. Chaudhuri, A. Sustaining cooperation in laboratory public goods experiments: A selective survey of the literature. Experimental Economics, 14 (2011), 47-83.

26. Chaudhuri, A., Graziano, S., and Maitra, P. Social learning and norms in a public goods experiment with inter-generational advice. Review of Economic Studies, 73 (2006), 357-380.

27. Chellappa, R., and Shivendu, S. Economic implications of variable technology standards for movie piracy in a global context. Journal of Management Information Systems, 20, 2 (Fall 2003), 137-168.

28. Chellappa, R., and Shivendu, S. Managing piracy: Pricing and sampling strategies for digital experience goods in vertically segmented markets. Information Systems Research, 16, 4 (December 2005), 400-417.

29. Cheng, H., Sims, R., and Teegen, H. To purchase or pirate software: An empirical study. Journal of Management Information Systems, 13, 4 (1997), 49-60.

30. Chiu, H., Hsieh, Y., and Wang, M. How to encourage customers to use legal software. Journal of Business Ethics, 80, 3 (July 2008), 583-595.

31. Cinyabuguma, M., Page, T., and Putterman, L. Cooperation under the threat of expulsion in a public goods experiment. Journal of Public Economics, 89 (2005), 1421-1435.

32. Clemons, E., Gu, B., and Lang, K. Newly vulnerable markets in an age of pure information products: An analysis of online music and online news. Journal of Management Information Systems, 19, 3 (Winter 2003), 17-41.

33. Coleman, J. Foundations of Social Theory. Cambridge: Harvard University Press, 1994.

34. Crawford, V., and Sobel, J. Strategic information transmission. Econometrica, 50, 6

(November 1982), 1431-1451.

35. Croson, R. Feedback in voluntary contribution mechanisms: An experiment in team production. Research in Experimental Economics, 8 (2001), 85-97.

36. Croson, R. Theories of commitment, altruism and reciprocity: Evidence from linear public goods games. Economic Inquiry, 45, 2 (April 2007), 199-216. 
37. Croson, R., Fatás, E., and Neugebauer, T. Excludability and contribution: A laboratory study in team production. Working paper, Wharton, (2006).

38. Croson, R., and Marks, M. Identifiability of individual contributions in a threshold public goods experiment. Journal of Mathematical Psychology, 42 (1998), 167-190.

39. Davis, D. and Holt, C. Experimental Economics. Princeton: Princeton University Press, 1993.

40. Dey, D., Lahiri, A., and Liu, D. Consumer learning and time-locked trials of software products. Journal of Management Information Systems, 30, 2 (Fall 2013), 239-267.

41. Diekmann, A. Volunteer's Dilemma. Journal of Conflict Resolution, 29, 4 (1985), 605-610.

42. Eagly, A., and Chaiken, S. Attitude structure and function. In Gilbert, D., Fiske, S., and Lindzey, G., (eds.), The Handbook of Social Psychology, 4th ed. Boston: McGraw-Hill, 1998, pp. 269-322.

43. Ellingsen, T., Johannesson, M., Tjøtta, S., and Torsvik, G. Testing guilt aversion. Games and Economic Behavior, 68, 1 (2012), 95-107.

44. Falkinger, J., Fehr, E., Gächter, S., and Winter-Ebmer, R. A simple mechanism for the efficient provision of public goods: Experimental evidence. American Economic Review, 90 (2000), 247-264.

45. Fehr, E., and Gächter, S. Cooperation and punishment in public goods experiments. American Economic Review, 90, 4 (2000), 980-994.

46. Fehr, E., and Schmidt, K. A theory of fairness, competition, and cooperation. The Quarterly Journal of Economics, 114, 3 (August 1999), 817-868.

47. Fischbacher, U. z-tree: Zurich toolbox for ready-made economic experiments.

Experimental Economics, 10, 2 (2007), 171-178.

48. Gächter, S., and Fehr, E. Collective action as a social exchange. Journal of Economic Behavior \& Organization, 39, 4 (July 1999), 341-369.

49. Gächter, S. and Herrmann, B. Reciprocity, culture and human cooperation: Previous insights and a new cross-cultural experiment. Philosophical Transactions of the Royal Society B, 364 (2009), 791-806.

50. Geng, X. and Lee, Y-J. Competing with piracy: A multichannel sequential search approach. Journal of Management Information Systems 30, 2 (Fall 2013), 159-184.

51. Government Accountability Office. Observations on efforts to quanitify the economic effects of conterfeit and pirated goods. (2010) (http://www.gao.gov/new.items/d10423.pdf, accessed January 3, 2012).

52. Glaeser, E., Laibson, D., Scheinkman, J., and Soutter, C. Measuring trust. The Quarterly Journal of Economics, 115, 3 (2000), 811-846.

53. Gopal, R., and Sanders, G. Preventive and deterrent controls for software piracy. Journal of Management Information Systems, 13, 4 (1997), 29-47.

54. Granovetter, M. The strength of weak ties. American Journal of Sociology, 78, 6 (1973), 1360-1380.

55. Gunter, W., Higgins, G., and Gealt, R. Pirating youth: Examining the correlates of digital music piracy among adolescents. International Journal of Cyber Criminology, 4, 1 and 2 (2010), 657-671.

56. Hashim, M.J., Kannan, K.N., and Maximiano, S. Information feedback, targeting, and coordination: An experimental study. Working Paper, (2013).

57. Hashim, M.J., Kannan, K.N., and Wegener, D.T. Nudging the digital pirate: A central role 
for moral obligations in determining intentions to engage in digital piracy. Working Paper, (2013).

58. Healy, A. How effectively do people learn from a variety of different opinions?

Experimental Economics, 12 (2009), 386-416.

59. Hinduja, S., and Higgins, G. Trends and patterns among music pirates. Deviant Behavior, 32 (2011), 563-588.

60. Hoffman, E., McCabe, K., and Smith, V. Social distance and other-regarding behavior in dictator games. The American Economic Review, 86, 3 (1996), 653-660.

61. Hunter, F. Socializing procedures in parent-child and friendship relations during adolescence. Developmental Psychology, 20, 6 (1984), 1092-1099.

62. Hunter, F. Adolescents' perception of discussions with parents and friends. Developmental Psychology, 21, 3 (1985), 433-440.

63. International Federation of the Phonographic Industry. Digital music report 2009., (2009)

(http://www.ifpi.org/content/library/DMR2009-real.pdf, accessed January 3, 2012).

64. Isaac, R., and Walker, J. Communication and free-riding behavior: The voluntary contribution mechanism. Economic Inquiry, 26, 4 (1988), 585-608.

65. Jones, C. Metallica rips napster. Wired Magazine, (April 13, 2000)

(http://www.wired.com/politics/law/news/2000/04/35670, accessed September 9, 2011).

66. Khouja, M., and Park, S. Optimal pricing of digital experience goods under piracy. Journal of Management Information Systems, 24, 3 (Winter 2008), 109-141.

67. Knopper, S. Rock and roll: Riaa's campus crackdown. Rolling Stone, 15. (April 5, 2007).

68. Kosfeld, M., Okada, A., and Riedl, A. Institution formation in public goods games.

American Economic Review, 99 (2009), 1335-1355.

69. Kosfeld, M., and Riedl, A. The design of (de)centralized punishment institutions for sustaining cooperation. In Raith, M., (ed.), Procedural Approaches to Conflict Resolution. Berlin and New York: Springer, 2004.

70. Kroll, S., Cherry, T., and Shogren, J. Voting, punishment, and public goods. Economic Inquiry, 45, 3 (July 2007), 557-570.

71. Ledyard, J. Public goods: A survey of experimental research. In Kagel, J. and Roth, A., (eds.), The Handbook of Experimental Economics. Princeton: Princeton University Press. 1995, pp. 111-194.

72. Leider, S., Möbius, M., Rosenblat, T., and Do, Q.-A. Directed altruism and enforced reciprocity in social networks. The Quarterly Journal of Economics, 124, 4 (2009), 1815-1851.

73. Masclet, D., Noussair, C., Tucker, S., and Villeval, M. The carrot or the stick:

Rewards,punishments, and cooperation. American Economic Review, 93 (2003), 366-380.

74. McAdam, D. and. Paulsen, R. Specifying the relationship between social ties and activism. American Journal of Sociology, 99, 3 (November 1993), 640-667.

75. McDowell, D., Parke, R., and Wang, S. Differences between mothers' and fathers' advice-giving style and content: Relations with social competence and psychological functioning in middle childhood. Merrill-Palmer Quarterly, 49 (2003), 55-76.

76. Mohlin, E., and Johannesson, M. Communication: Content or relationship? Journal of Economic Behavior \& Organization, 65 (2008), 409-419.

77. Moores, T., and Chang, J. Ethical decision making in software piracy: Initial development and test of a four-component model. MIS Quarterly, 30, 1 (March 2006), 167-180.

78. Nikiforakis, N. Punishment and counter-punishment in public good games: Can we really govern ourselves? Journal of Public Economics, 92 (2008), 91-11. 
79. Peace, A., Galletta, D., and Thong, J. Software piracy in the workplace: A model and empirical test. Journal of Management Information Systems, 20, 1 (Summer 2003), 153-177. 80. Peters, H., Ünür, A., Clark, J., and Schulze, W. Free-riding and the provision of public goods in the family: A laboratory experiment. International Economic Review, 45, 1 (February 2004), 283-299.

81. Polzer, J., Neale, M., and Glenn, P. The effects of relationships and justification in an interdependent allocation task. Group Decision and Negotiation, 2, 2 (1993), 135-148.

82. Poon, B., and Pittinsky, T. Upward advice transmission in the family: The role of gender in young adults giving advice to their parents. KSG Working Paper N. RWP05-012, (2005).

83. Purvis, B. To settle lawsuit, grandfather will speak against film piracy. Milwaukee Journal Sentinel, (December 19 2005).

84. Pyyny, P. Mpaa to fund anti-piracy education in schools. (October 24, 2003)

(http://www.afterdawn.com/news/article.cfm/2003/10/24/mpaa_to_fund_anti-piracy_education_i n_schools, accessed January 3, 2011).

85. Reuben, E., and Riedl, A. Public goods provision and sanctioning in privileged groups. Journal of Conflict Resolution, 53 (2009), 72-93.

86. Reuben, E., and van Winden, F. Social ties and coordination on negative reciprocity: The role of affect. Journal of Public Economics, 92 (2008), 34-53.

87. Recording Industry Association of America. Music rules! (2009)

(http://www.music-rules.com/index.html, accessed September 12, 2011).

88. Recording Industry Association of America. Campus downloading video. (2011a)

(http://www.campusdownloading.com/dvd.htm, accessed September 9, 2011).

89. Recording Industry Association of America. Who music theft hurts. (2011b)

(http://www.riaa.org/physicalpiracy.php?content_selector=piracy_details_online, accessed September 8, 2011).

90. Sell, J., and Wilson, R. Levels of information and contributions to public goods. Social Forces, 70, 1 (September 1991), 107-124.

91. Siwek, S. The true cost of sound recording piracy to the U.S. economy. Institute for Policy Innovation, Policy Report, 188 (August 2007).

92. Smith, E., and Benoit, D. Nine movie sites busted in pirating crackdown. The Wall Street Journal, (July 1, 2010) (http://online.wsj.com/article/SB10001424052748703426004575339120 611859094.html, accessed September 19, 2010).

93. Stewart-Robertson, T. Pupils struggle to take piracy subject seriously. The Scotsman, (January 6, 2010) (http://news.scotsman.com/education/Pupils-struggle-to-take-piracy. 5958006.jp, accessed January 3, 2011).

94. Sundararajan, A. Managing digital piracy: Pricing and protection. Information Systems Research, 15, 3 (2004), 287-308.

95. Sutter, M., Stefan, H., and Kocher, M. Choosing the carrot or the stick? Endogenous institutional choice in social dilemma situations. Review of Economic Studies, 77 (2010), 1540-1566.

96. Thong, J., and Yap, C. Testing an ethical decsion-making theory: The case of softlifting. Journal of Management Information Systems, 15, 1 (Summer 1998), 213-237.

97. Turrisi, R., Jaccard, J., Taki, R., Dunnam, H., and Grimes, J. Examination of the short-term efficacy of a parent intervention to reduce college student drinking tendencies. Psychology of Addictive Behavior, 15, 4 (2001), 366-372.

98. van Dijk, F., Sonnemans, J., and van Winden, F. Social ties in a public good experiment. 
Journal of Public Economics, 85, 2 (August 2002), 275-299.

99. van Dijk, F., and van Winden, F. Dynamics of social ties and local public good provision. Journal of Public Economics, 64 (1997), 323-341.

100. Varian, H. Markets for information goods. Working Paper, 1998.

101. Wang, J., Yang, Z., and Bhattacharjee, S. Same coin, different sides: Differential impact of social learning on two facets of music piracy. Journal of Management Information Systems, 28, 3 (Winter 2011), 343-384.

102. Weimann, J. Individual behavior in a free riding experiment. Journal of Public Economics, 54 (1994), 185-200.

103. Wood, M., Read, J., Mitchell, R., and Brand, N. Do parents still matter? Parent and peer influences on alcohol involvement among recent high school graduates. Psychology of Addictive Behaviors, 18, 1 (2004), 19-30.

104. Wortham, J. A political coming of age for the tech industry. The New York Times, (January 18 2012), A1.

\section{Appendix: Experiment Instructions}

\section{General Guidelines:}

Thank you for participating in this economic experiment. You will be paid in cash for your participation, and the amount of money you earn depends on the decisions that you and other participants make in individual rounds. Your final payment will be determined by three random draws done by the computer at the conclusion of the experiment. Each draw will correspond to one round of the experimental session. The average earnings over these three randomly selected rounds will be used to calculate your final payment. All earnings in this experiment will be presented to you in tokens and converted to US dollars at the conclusion of the experiment. The conversion rate, which is identical for everyone, is: 1 token per 0.8 US dollar.

You will never be asked to reveal your identity to anyone during the experiment. Your name will never be associated with any of your decisions. In order to keep your decisions private, please do not reveal your choices to any other participant.

You are welcome to ask questions at any time by raising your hand. Please wait for an experimenter to come to your seat before asking your question. While the experiment is in progress, please do not speak or in any other way communicate with other participants. This is important to the validity of the study.

\section{Specific Guidelines:}

In this experiment, you are taking part in a study about the decisions to purchase and download music. In the game, there are three types of participants: Record labels, music consumers, and non-consumers. The roles are fixed for the entire experiment and assigned in the following manner: University senior students will play the role of record labels; new students will be assigned the role of consumers; and parents will be given the role of non-consumers.

\section{In this experiment you are a music buyer}

In the experiment, you are going to play a game in a group of $\mathbf{9}$ participants. Each group will consist of 1 senior University student (a record label), 4 new students (the music consumers), and their respective parents (non-consumers). Groups are randomly formed in the beginning of the experiment and remain fixed for the entire experiment. Apart from your family member, you will never know the identities of the other participants in your group.

You will play a total of $\mathbf{2 0}$ rounds. Each round lasts 25 seconds. In each round, the 
player's decisions and earnings are as follows:

\section{Record Label:}

The record label does not make any decisions for the entire experiment. In the beginning of each round, the record label has 32 songs to sell. The record label gets 1 token for each song that is sold and 0.1 tokens for each unsold song.

Record Label's earnings in each round $=1 *$ number of songs sold in the round + $0.1 *$ number of songs not sold in the round

Music Buyers:

In this experiment you are a music buyer. In the beginning of each round, every music-buyer will receive an identical allowance of 8 tokens and 2 songs. Each round spans 25 seconds, within which you and every music buyer in your group will make a series of decisions. During each round please make as many decisions as possible. Specifically, your decision involves choosing one of the following options:

1. buy 1 song from the record label (if you have any tokens available)

2. download 1 song for free from the Internet (if there are new songs available)

3. do nothing

If you decide to buy a song from the record label, it costs you 1 token. Purchasing a song earns you 1.1 tokens.

The Internet source will have all the songs that you and other music buyers own, including those purchased. You can download a song from the Internet source so long as you do not own it. Because of the initial allowance of 2 songs, there are 6 other songs from the Internet source available for download at the beginning. As other music-buyers purchase songs, the number of songs available for download increases. Downloading a song from the Internet costs you nothing and earns you 0.5 tokens.

If you decide to do nothing you have no costs or earnings.

Remember that you will never be informed about the decisions of any other music-buyer in your group. Your earnings in each round will depend on the number of songs you initially owned, bought from the record label, and downloaded from the Internet source, plus the tokens you retained without purchasing.

Your earnings in each round $=8-1 *$ number of songs you bought in the round + $1.1 *$ number of songs you bought in the rounds $+0.5 *$ number of songs you downloaded in the round

At the end of each round, you will be informed about your own earnings for that round.

Non-consumers (parents):

Parents will get an allowance of 12 tokens per round. Your parent will never be informed about the choices you made in the experiment. However, at times parents are informed about the average number of songs downloaded from the Internet by your group and your parent will send you a message regarding the experiment.

\section{Figures and Tables}




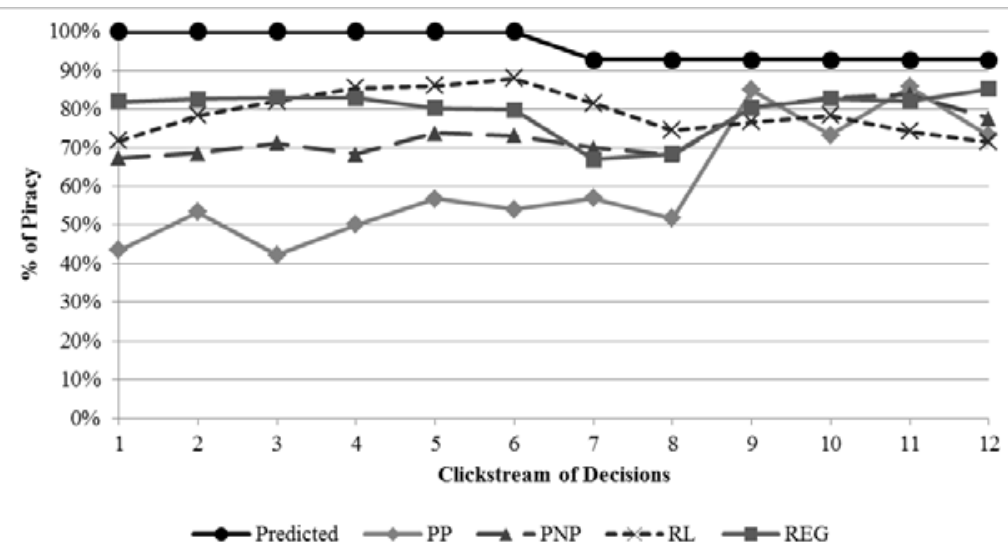

Figure 1: Comparison of Piracy Decisions to the Theoretical Prediction: Rounds 9 - 20

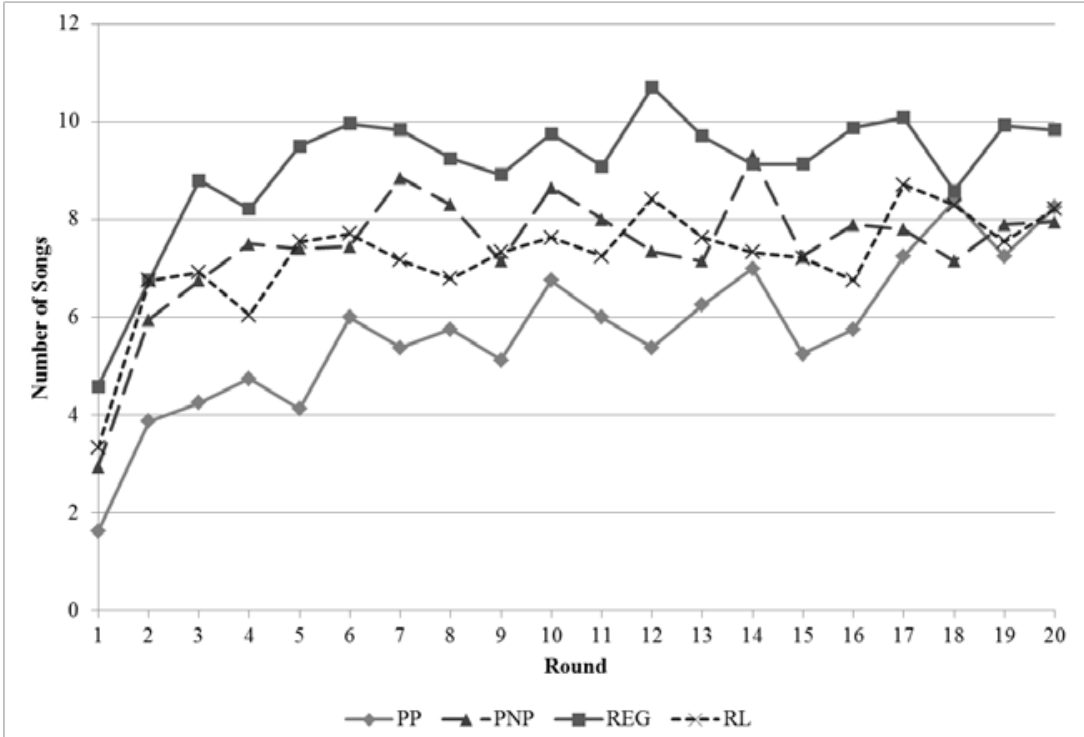

(a) Average \# of Pirated Songs 


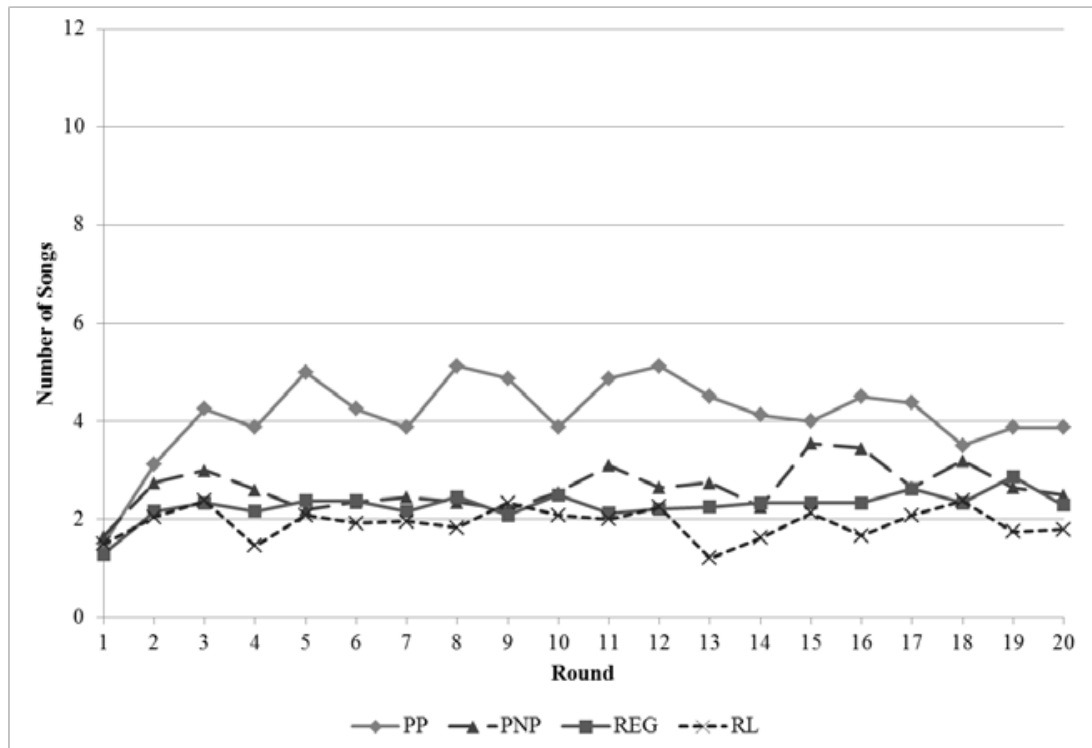

(b) Average \# of Purchased Songs

Figure 2: Aggregate Pirating and Purchasing Decisions per Round

Table 1: Matrix of Experimental Treatments

\begin{tabular}{|c|c|c|}
\hline & Stake in the Game & No Stake in the Game \\
\hline Social Tie & Parent With Punishment (PP) & Parent No Punishment (PNP) \\
\hline No Social Tie & Record Label (RL) & Industry Regulator (REG) \\
\hline
\end{tabular}

Table 2: Experimental Parameters

\begin{tabular}{|c|c|c|c|c|}
\hline \multirow{2}{*}{\multicolumn{2}{|c|}{ Subject Type }} & \multicolumn{2}{|c|}{ Endowment } & \multirow[b]{2}{*}{ Payoff } \\
\hline & & Tokens & Songs & \\
\hline \multicolumn{2}{|c|}{ Music Consumer } & 8 & 2 & $8+0.1 b_{i}+0.5 d_{i}$ \\
\hline \multicolumn{2}{|c|}{ Record Label } & 0 & 32 & $\left(32-\sum_{i=1}^{n} b_{i}\right) 0.1+\sum_{i=1}^{n} b_{i}$ \\
\hline \multirow{2}{*}{ Parent } & With Punishment & 12 & - & $12-0.6 d_{i}$ \\
\hline & No Punishment & 12 & - & 12 \\
\hline
\end{tabular}

Table 3: Aggregate Results Across Treatments

\begin{tabular}{|c|c|c|c|c|c|}
\hline \multicolumn{6}{|c|}{ Rounds 9 - 14} \\
\hline \multirow{2}{*}{$\begin{array}{c}\text { Source } \\
\text { of Advice }\end{array}$} & \multirow[b]{2}{*}{ Obs. } & \multicolumn{2}{|c|}{ Average \# of Songs } & \multirow{2}{*}{$\begin{array}{l}\text { Average } \\
\text { RL Profit }\end{array}$} & \multirow{2}{*}{$\begin{array}{c}\text { \% of } \\
\text { Piracy }\end{array}$} \\
\hline & & Purchased & Pirated & & \\
\hline PP & 48 & $4.56(3.46)$ & $6.08(5.69)$ & $19.63(2.97)$ & $57.1 \%$ \\
\hline PNP & 120 & $2.58(2.71)$ & $7.93(3.64)$ & $12.50(2.85)$ & $75.4 \%$ \\
\hline $\mathrm{RL}$ & 144 & $1.92(2.27)$ & $7.60(2.92)$ & $10.10(2.96)$ & $79.9 \%$ \\
\hline REG & 144 & $2.25(2.82)$ & $9.55(4.03)$ & $11.30(2.60)$ & $80.9 \%$ \\
\hline
\end{tabular}

\begin{tabular}{|c|c|c|c|c|c|}
\hline \multicolumn{7}{|c|}{ Rounds 15 - 20 } \\
\hline PP & 48 & $4.02(3.49)$ & $7.02(5.86)$ & $17.68(2.71)$ & $63.6 \%$ \\
\hline PNP & 120 & $3.00(3.04)$ & $7.66(4.59)$ & $14.00(3.00)$ & $71.9 \%$ \\
\hline RL & 144 & $1.97(2.26)$ & $7.78(2.85)$ & $10.28(3.20)$ & $79.8 \%$ \\
\hline REG & 144 & $2.47(3.06)$ & $9.57(4.32)$ & $12.08(3.32)$ & $79.4 \%$ \\
\hline
\end{tabular}

Standard deviations in parentheses. 
Table 4: Impact of Social Ties

\begin{tabular}{|c|c|c|c|c|c|}
\hline \multicolumn{6}{|c|}{ Rounds 9-14 } \\
\hline \multirow{2}{*}{$\begin{array}{c}\text { Source } \\
\text { of Advice }\end{array}$} & \multirow[b]{2}{*}{ Obs. } & \multicolumn{2}{|c|}{ Average \# of Songs } & \multirow{2}{*}{$\begin{array}{l}\text { Average } \\
\text { RL Profit }\end{array}$} & \multirow{2}{*}{$\begin{array}{c}\% \text { of } \\
\text { Piracy }\end{array}$} \\
\hline & & Purchased & Pirated & & \\
\hline Social Tie (PP \& PNP) & 168 & $3.15(3.07)$ & $7.40(4.38)$ & $14.54(4.32)$ & $70.2 \%$ \\
\hline No Social Tie (RL \& REG) & 288 & $2.08(2.56)$ & $8.57(3.65)$ & $10.70(2.85)$ & $80.5 \%$ \\
\hline
\end{tabular}

\begin{tabular}{|c|c|c|c|c|c|}
\hline \multicolumn{7}{|c|}{ Rounds 15 - 20 } \\
\hline Social Tie (PP \& PNP) & 168 & $3.29(3.20)$ & $7.48(4.97)$ & $15.05(3.35)$ & $69.4 \%$ \\
\hline No Social Tie (RL \& REG) & 288 & $2.22(2.70)$ & $8.68(3.76)$ & $11.18(3.38)$ & $79.6 \%$ \\
\hline
\end{tabular}

Standard deviations in parentheses.

Table 5: Impact of Stake in the Outcome

\begin{tabular}{|c|c|c|c|c|c|}
\hline \multicolumn{7}{|c|}{ Rounds 9 - 14 } \\
\hline $\begin{array}{c}\text { Source } \\
\text { of Advice }\end{array}$ & Obs. & \multicolumn{2}{|c|}{ Average \# of Songs } & $\begin{array}{c}\text { Average } \\
\text { RL Profit }\end{array}$ & $\begin{array}{c}\text { \% of } \\
\text { Piracy }\end{array}$ \\
\cline { 3 - 4 } & 192 & $2.58(2.85)$ & $7.22(3.84)$ & $12.48(5.09)$ & $73.7 \%$ \\
\hline Stake (PP \& RL) & 264 & $2.40(2.78)$ & $8.81(3.93)$ & $11.85(2.78)$ & $78.6 \%$ \\
\hline No Stake (PNP \& REG) & & &
\end{tabular}

\begin{tabular}{|c|c|c|c|c|c|}
\hline \multicolumn{7}{|c|}{ Rounds 15 - 20 } \\
\hline Stake (PP \& RL) & 192 & $2.48(2.76)$ & $7.59(3.83)$ & $12.13(4.45)$ & $75.4 \%$ \\
\hline No Stake (PNP \& REG) & 264 & $2.71(3.06)$ & $8.70(4.54)$ & $12.95(3.31)$ & $76.2 \%$ \\
\hline
\end{tabular}

Standard deviations in parentheses.

Table 6: Average Purchasing and Pirating: Rounds 9-20

\begin{tabular}{|c|c|c|c|c|c|}
\hline \multirow{2}{*}{$\begin{array}{c}\text { Source } \\
\text { of Advice }\end{array}$} & \multirow{2}{*}{ Obs. } & \multicolumn{2}{|c|}{ Average \# of Songs } & \multicolumn{2}{c|}{ Difference of } \\
\cline { 3 - 5 } & 96 & $4.29(0.35)$ & $6.55(0.59)$ & \multirow{2}{*}{$1.50(0.40)$} & \multirow{2}{*}{$-1.25(0.65)$} \\
\hline PP & 240 & $2.79(0.19)$ & $7.80(0.27)$ & & \multirow{2}{*}{$-1.87(0.30)$} \\
\hline PNP & 288 & $1.94(0.13)$ & $7.69(0.17)$ & \multirow{2}{*}{$-0.42(0.21)$} & \\
\hline RL & 288 & $2.36(0.17)$ & $9.56(0.25)$ & & \\
\hline
\end{tabular}

Standard errors of the means in parentheses.

Table 7: Immediate and Lasting Effects of Advice on Purchasing and Pirating

\begin{tabular}{|c|c|c|c|c|}
\hline \multirow{2}{*}{$\begin{array}{c}\text { Source } \\
\text { of } \\
\text { Advice }\end{array}$} & \multicolumn{2}{|c|}{ Diff. of Avg. Songs Purchased } & \multicolumn{2}{c|}{ Diff. of Avg. Songs Pirated } \\
\cline { 2 - 5 } & $\begin{array}{c}\text { Immediate } \\
\text { Rounds 6-8 vs. 9-11 }\end{array}$ & $\begin{array}{c}\text { Lasting } \\
\text { Rounds 6-8 vs. 12-14 }\end{array}$ & $\begin{array}{c}\text { Immediate } \\
\text { Rounds 6-8 vs. 9-11 }\end{array}$ & $\begin{array}{c}\text { Lasting } \\
\text { Rounds 6-8 vs. 12-14 }\end{array}$ \\
\hline PP & $-0.13(z=-0.89)$ & $-0.17(z=0.16)$ & $-0.25(z=-0.42)$ & $-0.50(z=-1.69)^{*}$ \\
\hline PNP & $-0.23(z=-1.98)^{* *}$ & $-0.17(z=-0.72)$ & $0.27(z=1.12)$ & $0.27(z=0.15)$ \\
\hline RL & $-0.24(z=-1.61)$ & $0.21(z=1.44)$ & $-0.18(z=-1.35)$ & $-0.57(z=-2.88)^{* * *}$ \\
\hline REG & $0.10(z=1.74)^{*}$ & $0.07(z=1.40)$ & $0.43(z=1.32)$ & $-0.17(z=-0.96)$ \\
\hline
\end{tabular}

\begin{tabular}{|c|c|c|c|c|}
\hline & $\begin{array}{c}\text { Immediate } \\
\text { Rounds 12-14 vs. 15-17 }\end{array}$ & $\begin{array}{c}\text { Lasting } \\
\text { Rounds 12-14 vs. 18-20 }\end{array}$ & $\begin{array}{c}\text { Immediate } \\
\text { Rounds 12-14 vs. 15-17 }\end{array}$ & $\begin{array}{c}\text { Lasting } \\
\text { Rounds 12-14 vs. 18-20 }\end{array}$ \\
\hline PP & $0.29(z=0.94)$ & $0.82(z=2.84)^{* * *}$ & $0.13(z=1.40)$ & $-1.75(z=-4.08)^{* * *}$ \\
\hline PNP & $-0.67(z=-3.07)^{* * *}$ & $-0.23(z=-0.05)$ & $0.28(z=1.71)^{*}$ & $0.27(z=1.12)$ \\
\hline RL & $-0.26(z=-0.44)$ & $-0.28(z=-0.94)$ & $0.24(z=-0.33)$ & $-0.22(z=-1.78)^{*}$ \\
\hline REG & $-0.17(z=-1.14)$ & $-0.24(z=-1.52)$ & $0.15(z=-0.15)$ & $0.40(z=0.78)$ \\
\hline
\end{tabular}

Differences in the means are computed as before advice minus after advice.

Wilcoxon signed-rank tests shown in parentheses. ${ }^{* * *} p<0.01$, ${ }^{* *} p<0.05$, ${ }^{*} p<0.10$. 